А.М. Панченко, Є.М. Зарічняк, А.О. Теличко, І.С. Огар, Д.С. Швець

Харківський національний університет Повітряних Сил ім. І. Кожедуба, Харків

\title{
ВИСОКОВОЛЬТНИЙ ПУСКОВИЙ ПРИСТРІЙ ДИЗЕЛЬ ГЕНЕРАТОРА
}

\begin{abstract}
Відомі ускладнення, що мають місие при запуску дизель генераторів, при низьких температурах, та незадовільному стані акумуляторів. 3 одного боку, ускладнення виникають за рахунок того, щзо при низьких температурах істотно збільшується момент опору на валу дизеля. Це обумовлено загуслим мастилом, зниженням температури в камері згорання. Як наслідок пускові оберти колінчатого валу збільшуються на 15-20\%. 3 іншого боку, при низьких температурах заряджений акумулятор може втрачати до 60\% своєї ємності. Обидва фактори об'єднуються і гарантований запуск дизель генератора не відбувається. Пропонується застосування пересувного пристрою, щзо здатен за 3-10 хв зарядити іоністор від мережі 220 В, та забезпечити живленням стартер дизель генератора. Перетворення електричної енергії відбувається без використання індуктивних елементів, щуо дало змогу істотно покращити його ваго габаритні показники. Найбільш ефективним пристрій стає при наявності декількох дизель генераторів. У випадку невдалого запуску, пристрій почергово доставляється до кожного дизель генератора, вихідними клемами приєднується безпосередньо до клем акумуляторів і виконується запуск. Перетоки енергї від іоністора до акумулятора, на иъьому етапі не відбуваються, оскільки внутрішній опір іоністора та стартера, на порядок менші від опору акумулятора. По необхідності підзарядка пристрою виконується від малопотужної мережі $220 B$. Процеси пуску дизель генератора описуються системою диферениійних рівнянь, щуо дає змогу отримати оптимальні співвідношення в залежності від типу дизель генератора. Отримані математичні залежності дозволяють оптимізувати процес пуску, иляхом використання магнітної енергї̈, щуо накопичується в індуктивних елементах стартера. Враховуючи малі значення внутрішнього опору стартера, акумулятора, іоністора та порівняно велику індуктивність стартера (якірна обмотка та обмотка збудження), можна досягти коливального процесу пуску. В такому разі, енергія накопичена в індуктивних елементах стартера на початковому етапі, буде додатково підтримувати його обертання. Подібна технологія пуску дозволить покращити ваго габаритні показники мобільного зарядного пристрою.
\end{abstract}

Ключові слова: іоністор, послідовний заряд, паралельний розряд, високовольтний запуск.

\section{Вступ}

Постановка проблеми. Надійна робота пересувних, автономних дизель генераторів, в умовах низьких температур є вкрай проблематичною. Це пов'язано, по перше з різким зростанням моменту опору на валу двигуна через збільшення в'язкості мастила, по друге - зниження температури акумулятора призводить до зменшення його ємності та зростання внутрішнього опору.

Якщо 3 першою причиною борються шляхом підігріву мастила та охолоджувальної рідини, то підігрів акумуляторів, як правило не передбачений. Низькі температури також суттєво впливають на значення пускових обертів.

На даний час все більшого розповсюдження набувають іоністори, елемент дещо подібний до конденсатора, але 3 аномально великою ємністю. Іоністорам також притаманний малий внутрішній опір, та стійка робота при низьких температурах. Використання їх в якості джерела пікового струму, для роботи стартера дасть змогу підвищити вірогідність гарантованого запуску дизель генератора при низьких температурах.

3 іншого богу впровадження іоністорів доцільне, якщо буде підвищена надійність запуску дизеля, але при цьому і зменшаться масо габаритні показники. А це буде можливим при наявності математичного апарату, що описує режими роботи стартера.

Аналіз останніх досліджень і публікацій. Для запуску дизельного двигуна необхідна порівняно незначна кількість енергії, але значна потужність. Свинцеві акумулятори навпаки, мають високі показники по питомій енергії та відносно низькі, по питомій потужності. Слід враховувати також, що по мірі зниження температури зростають мінімальні пускові оберти колінчатого валу [1].

Внаслідок цього при низьких температурах i високих стартерних струмах, акумулятор здатен віддати 10-15\% наявної енергії. Тобто більша частина енергії акумулятора не може бути задіяна при пуску [2]. 3 іншого боку, іоністор має низькі показники по питомій енергії але високі по питомій потужності, власне те, що необхідне для роботи стартера на протязі 3-10 сек. [3]. 
Співвідношення по ваго габаритних показниках наведені в табл. 1. Питомі показники по потужності іоністора істотно перевершують дані свинцевого акумулятора.

Таблиця 1

Порівняльні параметри свинцевого акумулятора та іоністора

\begin{tabular}{|c|c|c|c|c|}
\hline $\begin{array}{c}\text { № } \\
\text { 3/п }\end{array}$ & $\begin{array}{c}\text { Тип } \\
\text { накопичувача }\end{array}$ & кг & $W$ кДж & $N$ кВт \\
\hline 1. & $\begin{array}{c}\text { Свинцевий } \\
\text { акумулятор }\end{array}$ & 1 & 100 & 0,2 \\
\hline 2. & Іоністор & 1 & 40 & 10 \\
\hline
\end{tabular}

Джерело: розроблено авторами.

Також відома слаба залежність властивостей іоністора від низьких температур [4-5], що дозволяє їх використання при температурах нижче $-50^{0} \mathrm{C}$. Аналіз випадків невдалих запусків дизель генераторів показав, що не завжди вирішальне значення має низька температура оточуючого середовища. Відомо, що дизель генератор успішно може працювати при низьких температурах, лише його необхідно запустити.

При значній кількості дизель генераторів, вкрай складно досягти їх утримання в “гарячому резерві”.

Тому ряд виробників пропонують використовувати стартерні контейнери, де на базі іоністорів та малопотужного випрямляча облаштований пристрій для почергового пуску дизель генераторів [6]. Подібна технологія має свої позитивні сторони, але якщо необхідно запускати стартер потужністю до 2 кВт, а кількість техніки, яка потребує запуску перевершує 10-20 одиниць, то все це потребує часу. Автором [6] не вказано також який час необхідний для поповнення енергією іоністора. Очевидно для його швидкої зарядки до 24 В, необхідний і відповідний тран- сформатор і випрямляч. I звичайний трансформатор і випрямляч, при безпосередньому вмиканні не зможуть працювати, оскільки внутрішній опір іоністора становить порядку 0,0001-0,001 Ом. Тобто необхідна струмообмежувальна автоматика. Все це разом призведе до зростання ваго габаритних показників та обмеження мобільності.

Гарантованого запуску дизель генератора, 3 врахуванням умов покращення питомих показників, можна досягти лише враховуючи особливості роботи стартера при змінному характері його навантаження з боку колінчатого валу дизеля [7].

Мета статті - розробка мобільного, високовольтного без трансформаторного іоністорного пускового пристрою для почергового запуску дизель генераторів. Створення математичного апарату, що описує перехідні режими стартерних двигунів для узгодження їх параметрів з характеристиками іоністорного джерела живлення.

\section{Виклад основного матеріалу}

Пропонується створення пересувного стартового пристрою, для дизель генераторів, що розміщуються в боксах.

По мірі необхідності виріб заряджається від джерела змінної напруги 220 В. Час заряду визначається спроможністю місцевої мережі в межах 10-20 Хв.

Стартовий пристрій складається 3 випрямляча 220 В, трансформатора постійного струму, на базі іоністорів та системи управління. Сутність роботи пристрою полягає в наступному: від випрямляча іде заряд ємності в послідовному режимі з'єднання, по мірі їх заряду відбувається перемикання в паралельному режимі.

В певній мірі просліджується аналогія із звичайним трансформатором - в скільки разів зменшилась напруга в стільки разів збільшився струм.

Схема пристрою, представлена на рис. 1 .

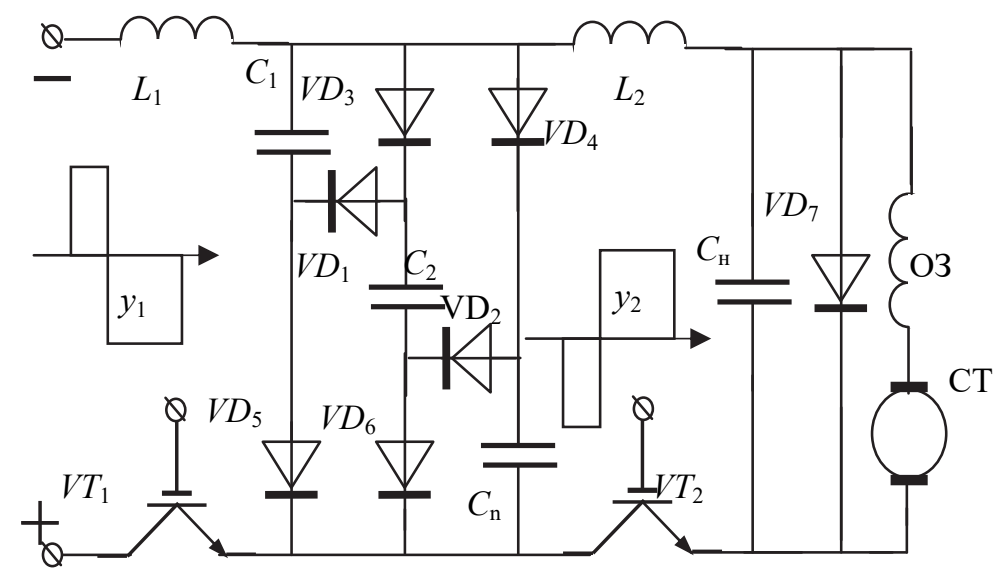

Рис. 1. Принципова схема трансформатора постійної напруги

Джерело: розроблено авторами. 
Принцип роботи наступний. Керуючий сигнал $y$ подається у протифазі на силові транзистори $V T_{1}$ i $V T_{2}$. При відкритті першого транзистора відбувається заряд ємностей в послідовному їх з'єднанні по колі $+, V T_{1}, C_{n}, V D_{2}, C_{2}, V D_{1}, C_{1}, L_{1}$. (Мається на увазі - клема акумулятора).

Індуктивність $L_{1}$, забезпечує зменшення кидка струму при розряджених ємностях. Смності однакові, отже на кожній із них встановлюється напруга, що дорівнює 1/3 частині від напруги джерела живлення. Збільшуючи чи зменшуючи чисельність ємностей можна змінювати коефіцієнт “трансформаціï” постійної напруги. При запиранні транзистора $V T_{1}$ відкривається транзистор $V T_{2}$ та відбувається розряд ємностей, які ввімкнені паралельно. При цьому напруга втричі зменшується, а ємність і кількість заряду відповідно в стільки ж разів збільшується.

Змінюючи частоту керуючих імпульсів та співвідношення тривалостей відкритого стану транзисторів можна плавно регулювати рівень вихідної напруги. На практиці, тонку доводку вихідної напруги можна регулювати співвідношеннями управляючих сигналів.

Кратне зменшення напруги забезпечується кількістю паралельно ввімкнутих ємностей $C_{1}-C_{n}$.

В якості накопичувача енергії пониженої напруги є іоністор $C_{n}$. Живлення стартера СТ відбувається безпосередньо від іоністора $C_{n}$. Функцію зворотного діоду виконує $V D_{7}$.

По мірі розряду іоністора і падінню струму накопичена магнітна енергія в індуктивних елементах стартера, буде підтримувати його обертання. Доцільно, в якості силових елементів $V T_{1}, V T_{2}$ використовувати IGBT транзистори, враховуючи пускові струми понад $700 \mathrm{~A}$.

3'ясуємо питання, щодо можливостей використання подібного перетворювача постійної напруги 3 точки зору потужностей, необхідних для стартера. На даний час, серійно випускаються потужні біполярні транзистори з ізольованим затвором (IGBT), які розраховані на роботу в ключовому режимі при струмах понад 1500 А та напругах понад 4500 В та частотах понад 20 кГц [8].

Параметри таких елементів цілком задовольнять вимоги до роботи ключових транзисторів $V T_{1}$, $V T_{2}$ в схемі (рис. 1).

Сучасні стартери дизель генераторів мають потужності в межах від 0,8 до 3 кВт, в залежності від марки дизеля [9].

Виходячи $з$ потужності 2 кВт отримаємо струм:

$$
I=\frac{P}{U}=\frac{3000}{30}=300 \mathrm{~A},
$$

де $P$ - орієнтовна потужність стартера;

$U$ - рівень напруги, до якої заряджається іоністор.

Певне перебільшення 30 В замість 24 В, обумовлено втратами на ключових елементах. Оскільки напруга живлення після випрямлення буде складати $\approx 250$ В орієнтовна кратність каскадів 6 .

Оскільки в режимі розряду ввімкнені 6 ємностей паралельно, то на кожну з них припадає по 50 А, а середня напруга повинна підтримуватися на рівні $30 \mathrm{~B}$.

Виберемо орієнтовну частоту комутації 1000 Гц. Тривалість циклу заряд - розряд буде дорівнювати

$$
T=\frac{1}{f}=\frac{1}{1000}=10^{-3} \mathrm{c} .
$$

Будемо вважати, що тривалість заряду дорівнює $1 / 6 \mathrm{~T}$, а тривалість розряду 5/6T, оскільки ємність заряду в 6 раз менша від ємності розряду.

3'ясуємо порядок значень ємності $C_{1} \div C_{n}$, який би на інтервалі часу $10^{-3} c$ підтримував напругу на навантаженні, рівній $90 \% U_{H}$. Будемо вважати припустимим пульсації напруги на навантаженні в межах $\pm 10 \% U_{H}$ [10]. Замінимо стартер еквівалентним активним навантаження і знайдемо його опір

$$
R_{H}=\frac{U_{H}}{I_{H}}=\frac{30}{300}=0,1 .
$$

Виходячи 3 експоненціального закону зміни струму в колі ємність - навантаження

$$
i(t)=\frac{1,1 U_{H}}{R_{H}} e^{-\frac{t}{R_{H} C_{H}}} .
$$

Знайдемо значення ємності, при якій за час $10^{-3} c$ напруга на навантаженні зменшиться від значення $1,1 U_{H}$ до значення $0,9 U_{H}$ [10]:

$$
\frac{0,9 U_{H}}{R_{H}}=\frac{1.1 U_{H}}{R_{H}} e^{-\frac{10^{-3}}{R_{H} C_{H}}} .
$$

Після перетворень отримаємо, що $0.82=e^{-\frac{10^{-3}}{R_{H} C_{n}}} ; \ln \frac{1}{0.82}=\frac{10^{-3}}{R_{H} C_{n}} \ln e ;$ $C_{n}=\frac{10^{-3}}{0.1 \cdot \ln 1.22}=0.05 \Phi$. 
Отже для частоти комутації 1000 Гц, значення ємності конденсаторів становить 0,05 Ф. Слід зауважити, що дані значення орієнтовні, оскільки слід враховувати значну індуктивність стартера і наявність зворотного діоду $V D_{7}$ (рис. 1) у зв'язку з чим ситуація з точки зору пульсацій буде дещо краща. Іоністор $C_{H}$ підтримує напругу самостійно лише в діапазоні часу, коли закритий транзистор $V T_{2}$, в інтервалі часу 2/3Т віддають енергію одночасно всі ємності. Це свідчить про те, що знайдені значення ємностей на частоті 1000 Гц, спроможні передати потужність, що дорівнює 2000 Вт.

Для забезпечення гарантованого режиму стартера на вказаних потужностях та врахування особливостей режиму його роботи необхідно створити математичний опис його роботи.

Технологія наступна:

- подається живлення, двигун виходить на певну швидкість, дизель запускається і стартер відмикається. Але цей перехідний режим складається 3 двох окремих режимів.

Перший, коли подається напруга на стартер, але він ще не обертається, відбувається електромагнітний перехідний процес. Він залежить від індуктивності стартера та активного опору кола стартера.

Другий, коли стартер починає обертатися до електромагнітного перехідного процесу додається електромеханічний. Він, в свою чергу обумовлений конструктивними властивостями стартера та джерела живлення.

Перший етап при нерухомому роторі, описується диференційним рівнянням

$$
U=i r_{0}+L \frac{d i}{d t}
$$

де $U$ - постійна напруга живлення;

$r_{0}$ - опір зарядного кола, що включає в себе $\mathrm{i}$ опір якоря та іоністора [11];

$$
\begin{aligned}
& L \text { - індуктивність двигуна; } \\
& t \text { - час. }
\end{aligned}
$$

Його рішення має вигляд

$$
i=\frac{U}{r_{0}}\left(1-e^{-\frac{r_{0}}{L} t}\right)
$$

На другому етапі, коли ротор набирає оберти необхідно враховувати противо-ЕРС (електрорушійна сила) ротора та механічні перехідні процеси, диференційне рівняння, що їх описує, має вигляд

$$
\left\{\begin{array}{l}
U=r i+L i^{\prime}+c_{e} \omega \\
c_{m} i=M_{0}+j \omega^{\prime}
\end{array},\right.
$$

де $c_{e}, c_{m}$ - конструктивні постійні коефіцієнти; $i, i^{\prime}$ - струм та його похідна;

$\omega, \omega^{\prime}$ - кутова швидкість та ії похідна;

$M_{0}$ - момент опору на валу двигуна;

$j$ - момент інерції ротора.

Таким чином на першому етапі процес описується рівнянням (6), а потім відповідно рівнянню (8). Кінцеві значення рівняння (6) являються початковими умовами для рівняння (8). Для знаходження значення струму, при якому ротор починає обертатися, необхідно прирівняти момент опору $M_{0}$ електромагнітному моменту $M_{e}$ :

$$
M_{e}=M_{0}=c_{m} i_{\text {об }} \text {. }
$$

Звідки знаходимо струм, що відповідає початковому руху ротора $i_{\text {об }}=\frac{M_{0}}{c_{m}}$, підставляючи зна-

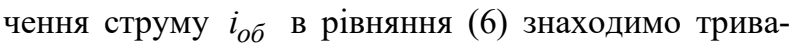
лість затримки між моментом подачі напруги і початком обертання

$$
t_{z}=\frac{L}{r_{0}} \ln \left(\frac{i_{k}}{i_{k}-i_{\text {об }}}\right) \text {. }
$$

Таким чином маємо закон зміни струму в момент вмикання і тривалість паузи до початку обертання ротора. Для знаходження закону зміни швидкості і струму під час обертання ротора необхідно розв'язати рівняння (7) відносно струму $i(t)$ та швидкості обертання $\omega(t)$. Виразимо струм та його похідну 3 другого рівняння системи $i=\frac{M_{0}}{c_{m}}+\frac{j}{c_{m}} \omega^{\prime} ; \quad i^{\prime}=\frac{j}{c_{m}} \omega^{\prime \prime}$ і підставимо їх в перше рівняння системи (6) отримаємо

$$
U=\frac{M_{0} r}{c_{m}}+\frac{j r}{c_{m}} \omega^{\prime}+\frac{L j}{c_{m}} \omega^{\prime \prime}+c_{e} \omega,
$$

приводимо до стандартного виду

$$
L j \omega^{\prime \prime}+j r \omega^{\prime}+c_{e} c_{m} \omega+M_{0} r-U c_{m}=0 .
$$

Початкові умови для швидкості $\omega\left(t_{z}\right)=0$, першу похідну для швидкості знаходимо із другого рівняння системи (7)

$$
\begin{aligned}
& c_{m} i_{\text {об }}=M_{0}+j \omega^{\prime} \\
& \omega^{\prime}=\frac{1}{j}\left(c_{m} i_{\text {об }}-M_{0}\right) .
\end{aligned}
$$

Для знаходження диференційного рівняння відносно струму виразимо швидкість із першого рівняння системи (6) та знайдемо іiі першу похідну 


$$
\omega=\frac{U}{c_{e}}-\frac{r}{c_{e}} i-\frac{L}{c_{e}} i^{\prime}, \quad \omega^{\prime}=\frac{r}{c_{e}} i^{\prime}-\frac{L}{c_{e}} i^{\prime \prime} .
$$

Підставивши значення першої похідної швидкості в друге рівняння (8) отримаємо

$$
c_{m} i=M_{0}-\frac{r}{c_{e}} j i^{\prime}-\frac{L}{c_{e}} j i{ }^{\prime \prime} .
$$

Після перетворень приводимо до стандартного виду

$$
L j i^{\prime \prime}+r j i^{\prime}+c_{m} c_{e} i-M_{0} c_{e}=0 .
$$

Отже маємо два рівняння другого порядку по струму та швидкості

$$
\left\{\begin{array}{l}
L j i^{\prime \prime}+r j i^{\prime}+c_{m} c_{e} i-M_{0} c_{e}=0 \\
L j \omega^{\prime \prime}+j r \omega^{\prime}+c_{e} c_{m} \omega+M_{0} r-U c_{m}=0
\end{array} .\right.
$$

Рішення системи диференційних рівнянь (8) для двох варіантів перехідного процесу приведено на рис. 2.

i(t)

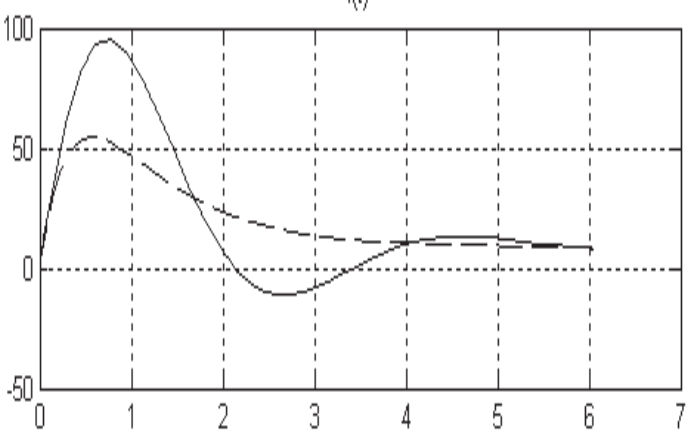

$m(t)$

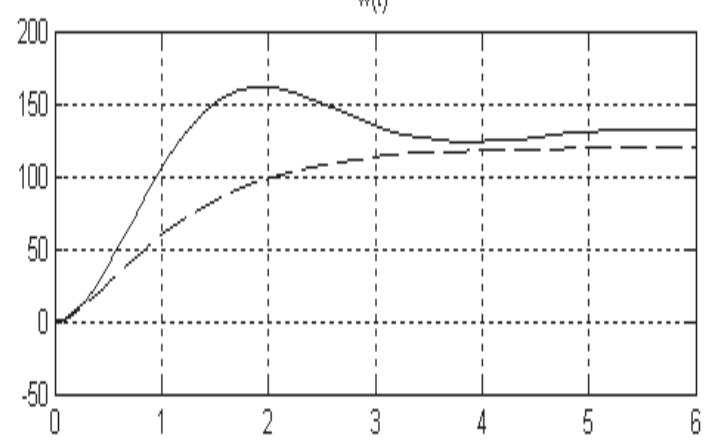

Рис. 2. Варіанти перехідних процесів при вмиканні стартера

Джерело: розроблено авторами.

В залежності від комбінації параметрів системи: джерело живлення-стартер-дизель, процеси можуть відбуватися як аперіодично так і періодично, враховуючі малі значення активного опору в стартерному колі, враховуючи іоністор [12] та індуктивність самого стартера.
На рис. 2 суцільною лінією показаний коливальний характер зміни струму на стартері, з зміною його полярності. Подібні явища не впливають на напрямок дії електромагнітного моменту, а отже і швидкості. Даний факт пов'язаний з тим, що стартер має послідовну систему збудження, отже при зміні напрямку струму в роторі змінюється і напрямок струму в колі збудження. Відомо, що електромагнітний момент дорівнює добутку величини струму на магнітний потік, а оскільки змінюються за знаком обидві величини, напрямок дії електромагнітного моменту стартера залишається не змінним.

Два варіанта зміни швидкості представлені на рис. 2 показують, що є можливість при тих же затратах енергії, в разі коливального процесу досягти більшої швидкості на валу 170 об/хв. При аперіодичному 120 об/хв.

\section{Висновки}

Запропонований прямий спосіб перетворення електричної енергії постійної напруги, без використання трансформатора і традиційних інверторів, дозволив покращити ваго габаритні показники та створити пересувну установку для запуску дизель генераторів. Переваги iї використання проявляються в умовах низьких температур та при незадовільному стані стартерних акумуляторів. Оскільки для заряду іоністорної пускової установки, від малопотужної мережі $220 \mathrm{~B}$, достатньо від $3 \div 10$ хв., то це дає можливість почергового ії використання на тих агрегатах, де запуск в штатному режимі не відбувся. Перевага запропонованого способу перетворення одного рівня напруги в іншу, полягає в тому, що відсутня проміжна ланка перетворення електричної енергії в магнітну і магнітну в електричну, як це відбувається в традиційних перетворювачах.

Оскільки режим роботи пристрою це сукупність перехідних, електромагнітних і електромеханічних процесів і він розраховується на широкий клас стартерів 3 різними параметрами, то для отримання його ефективної роботи необхідно було створити математичний опис його роботи. Отримана система диференційних рівнянь, що описує його режими з моменту подачі напруги, при нерухомому роторі стартера, з наступною його розкруткою.

Користуючись системою диференційних рівнянь, в залежності від характеристик стартерної системи дизель генератора, та вимог по ваго габаритних показниках, можна підібрати параметри для режиму пуску, коли струм в колі буде змінюватися коливально. Зазначений режим є найбільш економічним, оскільки використовується енергія магнітного поля накопичена стартером в початковій стадії пуску.

Слід зазначити, що враховуючи характер перехідного процесу рис. 2, можна впливати на зміну 
пускового моменту в часі, від пікового до плавного. А це в свою чергу впливає на експлуатаційні характеристики дизель генератора [10-11]. 3'являється можливість покращити надійність роботи стартера при низьких температурах, з точки зору оцінювання можливості прокрутки валу стартера [12].

\section{Список літератури}

1. Поляков Н.А. Система электростартерного пуска транспортных средств с применением комбинированного источника электрической энергии: дисс. ... канд. техн. наук / Н.А. Поляков. - М., 2005. - 170 с.

2. Щерба А.А. Закономерности повышения скорости нарастания разрядных токов в нагрузке при ограничении их максимальных значений / А.А. Щерба, Н.И. Супруновская // Техническая электродинамика. - 2012. - № 5. - С. 3-9.

3. Denshchikov K. Stacked Supercapacitor Technology - New Perspectives \& Chances / K. Denshchikov // Supercaps Europe - European Meeting on Supercapacitors: Development and Implementation in Energy and Transportation Techniques. Berlin, November 2005. - P. 285-297.

4. Lewandowski A. Practical and theoretical limits for electrochemical double-layer capacitor / A. Lewandowski, M. Galinski // Journal of Power Sources. - 2007. - № 173. - P. 822-828

5. Кузнецов В. Конденсаторы с двойным электрическим слоем (тонисторы): разработка и производство / В. Кузнецов. - СПб.: ОАО НИИ “Гринкорд”, 2005. - 5 с.

6. Denshchikov K. Problems of quality and reliability of stacked supercapacitors / K. Denshchikov, A. Gerasimov // 3rd European Symposium on Supercapacitors and Applications. - Roma, 6-7 November, 2008. - P. 335-341.

7. Ковалев В.Д. Противоаварийное управление электроэнергетическими системами / В.Д. Ковалев // Электричество. - 2001. - № 9.- С. 38-45.

8. Дьяконов В.П. Побистор или IGBT и имитационное моделирование устройств на них / В.П. Дьяконов, В.П. Побистор // Силовая электроника. - 2010. - № 5. - С. 24-32.

9. Использование молекулярных накопителей энергии, систем и агрегатов на их основе / В.П. Лобко, С.В. Кузнецов, А.А. Ионов, Д.А. Величко, М.В. Голиков. - М.: Наука, 2007. - 305 с.

10. Кононов Б.Т. Вибір показника для оцінювання технічного стану дизель-генератора / Б.Т. Кононов, О.І. Бондаренко // Збірник наукових праць Харківського національного університету Повітряних Сил. - 2017. - № 3(52). C. $113-117$.

11. Кононов Б.Т. Методика врахування крутильних коливань при визначенні ступеня нерівномірності частоти обертання валу дизель-генератора / Б.Т. Кононов, Ю.Д. Мусаїрова, А.О. Нечаус // Системи озброєння і військова техніка. - 2018. - № 4(56). - С. 100-107. https://doi.org/10.30748/soivt.2018.56.14.

12. Мусаїрова Ю.Д. Визначення амплітуд та частот крутильних коливань валопроводу дизель-генератора, в якому використовуються пристрої для гасіння коливань/Ю.Д. Мусаїрова // Збірник наукових праць Харківського національного університету Повітряних Сил. - 2019. - № 2(60). - С. 140-152. https://doi.org/10.30748/zhups.2019.60.18.

\section{Відомості про авторів:}

Панченко Анатолій Миколайович

кандидат технічних наук доцент

Харківського національного університету

Повітряних Сил ім. І. Кожедуба,

Харків, Україна

https://orcid.org/0000-0002-1280-2049

\section{Зарічняк Євгенія Михайлівна}

старший помічник начальника навчальної частини факультету післядипломної освіти

Харківського національного університету

Повітряних Сил ім. І. Кожедуба,

Харків, Україна

https://orcid.org/0000-0003-1620-529X

\section{Теличко Андрій Олексійович}

курсант

Харківського національного університету

Повітряних Сил ім. І. Кожедуба,

Харків, Україна

https://orcid.org/0000-0003-4634-0986

\section{Information about the authors:}

\author{
Anatoly Panchenko \\ Candidate of Technical Sciences Associate Professor \\ of Ivan Kozhedub Kharkiv \\ National Air Force University, \\ Kharkiv, Ukraine \\ https://orcid.org/0000-0002-1280-2049
}

\section{Yevheniia Zarichniak}

Senior Assistant

at Development Post Education

of Ivan Kozhedub Kharkiv

National Air Force University,

Kharkiv, Ukraine

https://orcid.org/0000-0003-1620-529X

\author{
Andrii Telychko \\ Cadet \\ of Ivan Kozhedub Kharkiv \\ National Air Force University, \\ Kharkiv, Ukraine \\ https://orcid.org/0000-0003-4634-0986
}




\section{Огар Ілля Сергійович}

курсант

Харківського національного університету

Повітряних Сил ім. І. Кожедуба,

Харків, Україна

https://orcid.org/0000-0003-4432-3672

\section{Швець Дмитро Сергійович}

курсант

Харківського національного університету

Повітряних Сил ім. І. Кожедуба,

Харків, Україна

https://orcid.org/0000-0002-3609-1827

\author{
Ilia Ohar \\ Cadet \\ of Ivan Kozhedub Kharkiv \\ National Air Force University, \\ Kharkiv, Ukraine \\ https://orcid.org/0000-0003-4432-3672
}

\author{
Dmytro Shvets \\ Cadet \\ of Ivan Kozhedub Kharkiv \\ National Air Force University, \\ Kharkiv, Ukraine \\ https://orcid.org/0000-0002-3609-1827
}

\title{
ВЫСОКОВОЛЬТНОЕ ПУСКОВОЕ УСТРОЙСТВО ДИЗЕЛЬ ГЕНЕРАТОРА
}

\author{
А.Н. Панченко, Е.М. Заричняк, А.А. Теличко, И.С. Огар, Д.С. Швець
}

Известные проблемы, которые имеют место при запуске дизель генераторов, при низких температурах, и неудовлетворительном состоянии аккумуляторов. С одной стороны, осложнения возникают за счет того, что при низких температурах существенно увеличивается момент сопротивления на валу дизеля. Это обусловлено загустевшим маслом, снижением температуры в камере сгорания. Как следствие пусковые обороты коленного вала увеличиваются на 15-20\%. С другой стороны, при низких температурах заряженный аккумулятор может терять до 60\% своей емкости. Оба фактора объединяются, и гарантированный запуск дизеля генератора не происходит. Предлагается применение передвижного устройства, которое способно за 3-10 мин. зарядить ионистор от сети 220 В, и обеспечить питанием стартер дизель генератора. Превращение электрической энергии происходит без использования индуктивных элементов, что дало возможность существенно улучшить его массогабаритные показатели. Наиболее эффективным устройство становится при наличии нескольких дизель генераторов. В случае неудачного запуска, устройство поочередно доставляется к каждому дизель генератору, выходными клеммами присоединяется непосредственно к клеммам аккумуляторов и выполняется запуск. Перетекания энергии от ионистора к аккумулятору, на этом этапе не происходят, поскольку внутреннее сопротивление ионистора и стартера, на порядок меньше от сопротивления аккумулятора. По необходимости подзарядка устройства выполняется от маломощной сети 220В. Проиессы пуска дизель генератора описываются системой дифференциальных уравнений, которая дает возможность получить оптимальные соотномения в зависимости от типа дизель генератора. Полученные математические зависимости позволяют оптимизировать процесс пуска, путем использования магнитной энергии, которая накапливается в индуктивных элементах стартера. Учитывая малые значения внутреннего сопротивления стартера, аккумулятора, ионистора и сравнительно большую индуктивность стартера (якорная обмотка и обмотка возбуждения), можно достичь колебательного процесса пуска. В таком случае, энергия накоплена в индуктивных элементах стартера на начальном этапе, будет дополнительно поддерживать его вращение. Подобная технология пуска позволит улучшить массогабаритные показатели мобильного зарядного устройства.

Ключевые слова: ионистор, последовательный заряд, параллельный разряд, высоковольтный запуск.

\section{HIGH-VOLTAGE STARTING DEVICE OF DIESEL OF GENERATOR}

\author{
A. Panchenko, Ye. Zarichniak, A. Telychko, I. Ohar, D. Shvets
}

Well-known problems that take place at a start diesel of generators, at subzero temperatures, and unsatisfactory state of accumulators. From one side, complications arise up due to that at subzero temperatures substantially the moment of resistance increases on the billow of diesel. It contingently thickening oil, decline of temperature in a combustion chamber. As a result the starting turns of knee billow increase on 15-20\%. On the other hand, at subzero temperatures the charged accumulator can lose to $60 \%$ of the capacity. Both factors unite, and the assured start of diesel of generator does not take place. Application of movable device that is capable after 3-10 min to charge super condenser from a network 220 In is offered, and to provide a feed a starter diesel of generator. Transformation of electric energy takes place without the use of inductive elements that gave possibility substantially to improve it massoverall indexes. Most effective a device becomes at presence of a few the diesel of generators. In case to the unsuccessful start, a device by turns is delivered to each the diesel to the generator, joins output terminals directly the terminals of accumulators and executed start. Exchange of energy from super condenser to the accumulator, on this stage does not take place, as internal resistance of super condenser and starter, on an order less from resistance of accumulator. Of necessity sub charge of device is executed from the low-powered network of 220B. Starting processes the diesel of generator is described by the system of differential equalizations that gives an opportunity to get optimal correlations depending on a type diesel of generator. The got mathematical dependences allow optimizing a starting process, by the use of magnetic energy that accumulates in the inductive elements of starter. Taking into account the small values of internal resistance of starter, accumulator, super condenser and comparatively large inductance of starter (anchor puttee and puttee of excitation), it is possible to attain a shake process of starting. At that rate, energy is accumulated in the inductive elements of starter on the initial stage, his rotation will additionally support. Similar technology of starting will allow to improve the mass overall indexes of mobile charge device.

Keywords: ionizer, series charge, parallel discharge, high voltage start. 